\title{
Characteristics and factors influencing the natural regeneration of Larix principis-rupprechtii seedlings in northern China
}

\author{
Weiwen Zhao $^{1}$, Wenjun Liang ${ }^{\text {Corresp., } 1}$, Youzhi Han ${ }^{\text {Corresp., } 1}$, Xi Wei ${ }^{1}$ \\ ${ }^{1}$ College of Forestry, Shanxi Agricultural University, Taigu, China \\ Corresponding Authors: Wenjun Liang, Youzhi Han \\ Email address: liangwenjun123@163.com, hanyouzhi@sxau.edu.cn
}

Larix principis-rupprechtii is an important and widely distributed species in the mountains of northern China. However, it has inefficient natural regeneration in many stands and difficulty recruiting seedlings and saplings. In this study, we selected six plots with improved naturally-regenerated $L$. principis-rupprechtii seedlings. A point pattern analysis (pair-correlation function) was applied to identify the spatial distribution pattern and correlation between adult trees and regenerated seedlings mapped through $X / Y$ coordinates. Several possible influencing factors of $L$. principis-rupprechtii seedlings' natural regeneration were also investigated. The results showed that the spatial distribution patterns of Larix principis-rupprechtii seedlings were concentrated 0-5 m around adult trees when considering the main univariate distribution type of regeneration. There was a positive correlation at a scale of 1.5-4 $\mathrm{m}$ between seedlings and adult trees according to bivariate analyses. When the scale was increased, these relationships were no longer significant. Generally, adult trees raised regenerated L. principis-rupprechtii seedlings at a scale of 1.5-4 m. Principal component analysis showed that the understory herb diversity and litter layer had a negative correlation with the number of regenerated seedlings. There was also a weak relationship between regenerated numbers and canopy density. This study demonstrated that the main factors promoting natural regeneration were litter thickness, herb diversity, and the distance between adult trees and regenerated seedlings. Additionally, these findings will provide a basis for the late-stage and practical management of natural regeneration in northern China's mountain ranges. 


\section{Characteristics and factors influencing the natural}

\section{2 regeneration of Larix principis-rupprechtii seedlings in}

\section{3 northern China}

4 Weiwen Zhao, Wenjun Liang*, Youzhi Han*, and Xi Wei

5 College of Forestry, Shanxi Agricultural University, Taigu, China

$6{ }^{*}$ Corresponding Author:

7 Wenjun Liang and Youzhi Han

8 Taigu, Shanxi, China

9 Email address: liangwenjun123@163.com (W. L.) and hanyouzhi@sxau.edu.cn (Y. H.)

\section{Abstract}

12 Larix principis-rupprechtii is an important and widely distributed species in the mountains of northern China. However, it has inefficient natural regeneration in many stands and difficulty recruiting seedlings and saplings. In this study, we selected six plots with improved naturallyregenerated L. principis-rupprechtii seedlings. A point pattern analysis (pair-correlation function) was applied to identify the spatial distribution pattern and correlation between adult trees and regenerated seedlings mapped through $\mathrm{X} / \mathrm{Y}$ coordinates. Several possible influencing factors of $L$. principis-rupprechtii seedlings' natural regeneration were also investigated. The results showed that the spatial distribution patterns of Larix principis-rupprechtii seedlings were concentrated $0-5$ $\mathrm{m}$ around adult trees when considering the main univariate distribution type of regeneration. There was a positive correlation at a scale of $1.5-4 \mathrm{~m}$ between seedlings and adult trees according to bivariate analyses. When the scale was increased, these relationships were no longer significant. Generally, adult trees raised regenerated L. principis-rupprechtii seedlings at a scale of 1.5-4 m. Principal component analysis showed that the understory herb diversity and litter layer had a negative correlation with the number of regenerated seedlings. There was also a weak relationship between regenerated numbers and canopy density. This study demonstrated that the main factors promoting natural regeneration were litter thickness, herb diversity, and the distance between adult trees and regenerated seedlings. Additionally, these findings will provide a basis for the late-stage and practical management of natural regeneration in northern China's mountain ranges. Keywords Natural regeneration, Larix principis-rupprechtii, Spatial point pattern, Herb diversity, Litter thickness 


\section{Introduction}

34 Plants are vital for the soil-plant-atmosphere-continuum (SPAC), which is responsible for the production of high quantities of timber and other practical products (Liu et al., 2019; Peng et al., 2008; Wei et al., 2010). Previous research showed that forest reconstruction depends on natural recruitment across all plantations (Dong et al., 2018; Man et al., 2013; Mc et al., 2015; Seiwa et al., 2012; Stoyan et al., 1994), and also suggested that natural regeneration was very effective in forest development. Regeneration and development restore degraded forest ecosystems to ones with high biodiversity and an ecological quality that is in line with those undergoing natural regeneration, which can save time and costs and increase biodiversity (Ram et al., 2014). Seedlings are more stable in forest ecosystems following natural regeneration. However, the regeneration in most plantations has become difficult due to artificial intervention and over-exploitation (Gao et al., 2020; Hernandez-Barrios et al., 2015; Wang et al., 2017), which cause spatial condition stress for regenerated seedlings and intense thinning density, which removes the available seed source (Guo \& Wang, 2019). Previous studies have shown that natural regeneration is more efficient than traditional planting at maintaining ecological sustainability because of the increase of young trees and the replacement of old and dead trees (B et al., 2016; Christian et al., 2018; Singh \& Rawat, 2012). Therefore, it is necessary to investigate naturally regenerated seedlings when aiming to balance production, recover ecosystems, and provide solutions for forest management.

To identify the factors that affect natural regeneration, many researchers have studied stand structure, canopy density, canopy gap, and thinning intensity in forests and found that the decrease of regenerated seedlings were affected by increases in canopy density, canopy gaps, and thinning intensity (Chen \& Cao, 2014; Wang et al., 2017; Wang et al., 2019). Larix principis-rupprechtii is an important species when discussing afforestation due to its high growth rate, good soil erosion resistance, fine drought tolerance, and wide distribution in the mountains of northern China. The regeneration failures of $L$. principis-rupprechtii plantations from the germination to seedling maturity stages have become a crucial issue in China (Wenjun $\& X i, 2020$ ), but the characteristics and influencing factors of their seedlings' natural regeneration have remained undetermined. Therefore, this study was conducted to analyze the spatial patterns between L. principisrupprechtii seedlings and adult trees, as well as the additional factors that affect its regeneration.

The spatial pattern of a species is very important for its ecological processes. Studies have suggested the importance of regeneration spatial patterns for plant dynamics (Camarero et al., explain the influence of adult trees on seedlings. There are also many biotic and abiotic factors 
67 litter thickness and herb coverage, which are controlled by the mechanisms of seed diffusion and 68 the appropriate microsites for regeneration (Devaney et al., 2014). There are two forms of 69 population ecological relationships in spatial patterns: spatial distribution and spatial correlation.

70 Studies have shown that aggregated, random, and regular spatial distributions are positively, 71 negatively, and insignificantly correlated, respectively, with spatial relationships, which explains 72 the spatially horizontal structure and interactions between population and environmental factors 73 (Seidler \& Plotkin, 2006; Wang et al., 2010). Although the number of scattered seeds from most 74 plant species tends to decrease with the increased distance from adult trees, the negative 75 relationship between the number of seedlings and the distance from adult trees has not been 76 confirmed (Devaney et al., 2014; Janzen, 1970). Spatial patterns can reveal the potential factors 77 of these distribution patterns and their correlation, as well as help predict the direction of 78 population evolution processes, such as recruitment, regeneration, and dying.

Traditional analysis methods based on spatial distribution patterns, such as the non-sample method and variance block analysis, are not able to fully reflect spatial distribution because spatial patterns and correlations depend on population density and spatial scale (Haase, 1995; He et al., 1997; Itoh et al., 1997). To eliminate the limitations of these methods, Ferrier et al. (2002) and D. (1977) proposed an improved method based on individual digital plant location information, where they took each individual as a point in two-dimensional space, printed the spatial distribution map, and analyzed the spatial pattern. This method has overcome the shortcomings of the single scale used by traditional methods, and it also can provide comprehensive information on the distance between points and spatial pattern characteristics at any scale (Frost \& Rydin, 2000; Zhang \& Meng, 2007). Point pattern analysis provides a beneficial construction to analyze discrete points in space (Wiegand et al., 2006). Some researchers have extended it to include the K function K(r) and pair-correlation function $\mathrm{g}(\mathrm{r})$, which have been confirmed as valuable in forest ecology $(D$., 1977; Hambly et al., 1994; Stoyan et al., 1994). Barbeito et al. (2008) used spatial point analysis to study canopies in different aged structures and found that an uneven and multi-aged management system was the best for regenerated seedlings. Therefore, in this study, we used a spatial point pattern to analyze the relationship between seedlings and adult trees and the distance between them.

In this study, the pair-correlation function of the spatial point pattern analysis method was adopted to analyze the spatial distribution pattern and correlation between L. principis-rupprechtii adult trees and seedlings. Principal component analysis was used to identify the factors that affect 
101 the regeneration of seedlings; and (3) other environmental factors affect the natural regeneration

102 of seedlings. In the study area, regenerated L. principis-rupprechtii occupied a small region with

103 only a few adult trees. To test these hypotheses, we selected six sampling plots with greater number

104 of naturally regenerated L. principis-rupprechtii seedlings in the Guandi Mountains. After

105 analysis, the main factors affecting seedling regeneration were identified. The findings can provide

106 guidance for the later stage management of natural regeneration and promote the maintenance and

107 development of L. principis-rupprechtii plantations in the mountains of northern China.

108

\section{Materials \& Methods}

\section{Study site}

111 This study was conducted in the Guandi Mountains, Jiaocheng county, Lvliang country, Shanxi

112 Province $\left(111^{\circ} 22^{\prime}-111^{\circ} 33^{\prime} \mathrm{E}, 37^{\circ} 45^{\prime}-37^{\circ} 55^{\prime} \mathrm{N}\right)$ (Yang et al., 2017). The annual, minimum, and

113 maximum temperatures are $4.3^{\circ} \mathrm{C},-29.1^{\circ} \mathrm{C}$, and $17.7^{\circ} \mathrm{C}$, respectively. The average, minimum, and

114 maximum atmospheric pressure is $936.6 \mathrm{hPa}, 936.4 \mathrm{hPa}$, and $936.8 \mathrm{hPa}$, respectively. The average

115 water vapor pressure is $5.3 \mathrm{hPa}$. The average annual precipitation is $822 \mathrm{~mm}$, and evaporation is

$1161,268 \mathrm{~mm}$. The altitude is between 1,500 and $2,831 \mathrm{~m}$. The area has a temperate continental

117 monsoon climate. The soil is mainly mountain cinnamon soil, cinnamon soil, and brown soil (Yang

118 et al., 2017).

119 The forests are made up of dominant plants (L. principis-rupprechtii, Pinus tabuliformis,

120 Picea wilsonii, Picea meyeri, Picea asperata, and Populus simonii), shrubs (Acer tataricum subsp.

121 ginnala, Rosa multiflora, Spiraea salicifolia, Clematis florida, and Berberis amurensis), and grass

122 (Fragaria orientalis, Geranium wilfordii, Chrysanthemum chanetii, Lathyrus humilis, Rubia

123 cordifolia, Bupleurum smithii, and Thalictrum aquilegiifolium).

\section{Experimental design}

125 We investigated L. principis-rupprechtii seedling regeneration in the Guandi Mountains in a 126 research area of $2 \mathrm{hm}^{2}$ in August 2020. The forest area was a plantation that did not have artificial

127 intervention or management. Six fixed $40 \times 40 \mathrm{~m}$ plots were selected (Fig. 1). The regeneration

128 degree was evaluated (high $=$ number of regenerated seedlings $>5,000$ tree/ha, medium $=$ number 129 of regenerated seedlings between 3,000 and 5,000 tree/ha, and low $=$ number of regenerated 130 seedlings between 2,500 and 3,000 tree/ha). In order to efficiently identify useful methods to 131 stimulate natural regeneration, we studied the sampling plots with high regeneration densities, and 132 then analyzed the effects of the naturally regenerated seedlings.

\section{Data collection}

134 Field measurements were carried out in six plots between August 1 and August 30, 2020. After 
135 the plots were laid out, we measured their land parameters, including aspect, slope, elevation,

136 longitude, latitude, and canopy density (Table 1). Simultaneously, all L. principis-rupprechtii

137 individuals were mapped in a plane-coordinate system. The coordinates of each L. principis-

138 rupprechtii individual was measured using a tape and compass. We recorded each adult tree's

139 growth parameters, including height, diameter, breast height, and crown. The distances between

140 L. principis-rupprechtii seedlings and the adult trees were recorded. Two categories were

141 established: seedlings $(0.3 \mathrm{~m}<$ height $<2.5 \mathrm{~m})$ and saplings (height $\geq 2.5 \mathrm{~m})$. Five sampling points

$142(1 \times 1 \mathrm{~m})$ in each plot were selected for herb species investigation using a $\mathrm{X}$ shape sampling

143 method. Each herb species' height, number, and coverage was recorded before bagging and

144 weighing. The significant value was adopted to measure diversity indices such as the Simpson

145 index, Shannon-Wiener index, and Pielou index. The shrub species across five quadrats $(5 \times 5 \mathrm{~m})$

146 were then investigated and recorded using X-shape sampling. Five $30 \times 30 \mathrm{~cm}$ litter sampling

147 points near each herb and shrub sampling plot were additionally investigated. After the stones were

148 removed, the undecomposed and semi-decomposed litter was classified, bagged, weighed, and

149 labeled for further laboratory analysis. Five litter samples and five herb samples were collected

150 from each plot.

\section{Spatial pattern statistical analysis}

152 Our point pattern analysis illustrated the spatial relationship and described the effect of distance

153 between the L. principis-rupprechtii adult trees and seedlings. The null model identified potential 154 differences in this spatial distribution. Pair-correlation function g(r) combined with Ripley's K 155 function showed the spatial relationship of different species. The random labeling null model was 156 utilized to complete spatial randomness (CSR). The expected number of points at distance $d$ and a 157 short analysis area, $\mathrm{K}(\mathrm{d})$, were calculated by:

$$
\mu \mathrm{K}(\mathrm{d})=\sum \sum \frac{\mathrm{w}_{\mathrm{ij}}(\mathrm{d})}{\mathrm{n}}(1)
$$

159 where $\mu$ is the density of regenerated seedlings per plot, $\mathrm{n}$ is the number of trees, and $\mathrm{w}_{\mathrm{ij}}(\mathrm{d})$ is a 160 weight function that considers the edge effect and represents the reciprocal of the number of circles 161 centered on $\mathrm{i}$ (the radius is the distance from $\mathrm{i}$ to $\mathrm{j}$ ) falling into the area (Barbeito et al., 2008).

162 The pair-correlation function $\mathrm{g}(\mathrm{r})$ assessed the critical range of regenerated clusters, which 163 was more efficient compared to the $K$ function that removed the scale dependence of $K(d)$. The 164 pair-correlation was the derivate of the $\mathrm{K}$ function, calculated by:

$$
\mathrm{g}(\mathrm{r})=\mathrm{K}^{\prime}(\mathrm{r}) / 2 \pi \mathrm{r}(2)
$$


166 where $\mathrm{r}$ is the spatial scale, and dot is the sampling circle with the target trees. $\mathrm{g}(\mathrm{r})>1, \mathrm{~g}(\mathrm{r})=1$, and

$167 \mathrm{~g}(\mathrm{r})<1$ indicated the pattern aggregation, randomness, and regularity, respectively, on the scale $\mathrm{r}$.

168 The spatial relationship between seedlings and trees was analyzed using the $\mathrm{g}_{12}(\mathrm{r})$ function:

$$
\mathrm{g}_{12}(\mathrm{r})=\mathrm{dK}_{12}(\mathrm{r}) /(2 \pi \mathrm{r} \cdot \mathrm{d}(\mathrm{r}))(3)
$$

170

where $g_{12}(r)=1, g_{12}(r)>1$, and $g_{12}(r)<1$ indicate insignificant, positive, and negative correlations, respectively, between two different species on the scale $r$. These species were selected and combined within the two defined categories (seedlings and adult trees) to analyze their relationship.

174 The spatial relationship between the regenerated seedlings and adult trees was examined using CSR. Random labeling is not commonly used in sample plots. Consequently, we adopted a case-control design with L. principis-rupprechtii seedlings as pattern 1 (the control pattern) and $L$. principis-rupprechtii adult trees as pattern 2 (case). $\mathrm{g}_{12}(\mathrm{r})$ provided insight into the spatial distribution of L. principis-rupprechtii seedlings around adult trees. At a given scale, if $\mathrm{g}_{12}(\mathrm{r})$ was above the confidence envelope, L. principis-rupprechtii seedlings were positively associated with L. principis-rupprechtii adult trees on the scale $\mathrm{r}$. However, if $\mathrm{g}_{12}(\mathrm{r})$ was below the confidence envelope, that showed a negative association between seedlings and trees.

All analyses were conducted using the Programita software package and Origin 2021 software (Wiegand \& Moloney, 2004). The scale $\mathrm{r}$ represented spatial scales within $20 \mathrm{~m}$

184 (calculated up to half of the shortest side of the sampling plots). We used a $1 \mathrm{~m}$ cell scale and calculated the statistics up to a scale $\mathrm{r}$ of $20 \mathrm{~m}$ in view of plot size. One hundred and ninety-nine Monte Carlo simulations with a significance level of $99 \%$ were used to determine whether the species distribution pattern and correlation were significant (Wiegand \& Moloney, 2004).

\section{Results}

Spatial distribution patterns of L. principis-rupprechtii seedling populations across different sampling plots

192 Only seedlings of the same age and adult trees were found in the sampling plots, and no saplings were found. We observed that L. principis-rupprechtii seedlings and L. principis-rupprechtii adult trees were randomly distributed ( I -VI) (Fig. 2). There was low spatial heterogeneity between seedlings and trees. We additionally explored L. principis-rupprechtii seedling spatial patterns across six sampling plots, and the $\mathrm{g}(\mathrm{r})$ function analysis results showed that the spatial distribution 
198 showed aggregated distribution at a scale of $0-17.5 \mathrm{~m}$, and random distribution at a scale of $17.5-$

19920 m (Fig. 3- I ). L. principis-rupprechtii seedlings in plot II showed aggregated distribution at

200 a scale of $0-15 \mathrm{~m}$ (Fig. 3- I ). L. principis-rupprechtii seedlings in plot III showed aggregated

201 distribution at a scale of $0-9 \mathrm{~m}$, random distribution at a scale of $10-12.5 \mathrm{~m}$, and regular

202 distribution at a scale of $12.5-20 \mathrm{~m}$ (Fig. 3-III). L. principis-rupprechtii seedlings in plot IV

203 showed aggregated distribution at scales of $0-5 \mathrm{~m}$ and $7.8-17.5 \mathrm{~m}$, and random distribution at a

204 scale of 5-7.8 m (Fig. 3-IV). L. principis-rupprechtii seedlings in plot V showed aggregated

205 distribution at scales of 0-9.5 m and 10-19 m (Fig. 3-V). L. principis-rupprechtii seedlings in

206 plot VI showed aggregated distribution at a scale of $0-5 \mathrm{~m}$ and random distribution at a scale of

207 5-20 m (Fig. 3-VI). Generally, L. principis-rupprechtii seedlings showed aggregated distribution

208 at small scales and random or regular distribution with increased spatial scale. The scatter 209 distribution of populations in the sampling plots (Fig. 3) also showed that L. principis-rupprechtii

210 seedlings in different sample plots were clustered in the Guandi Mountains.

211 Bivariate spatial analysis of $L$. principis-rupprechtii seedlings and adult trees in 212 different sampling plots

213 Our spatial correlation analysis of L. principis-rupprechtii adult trees and seedlings showed that

214 their spatial correlations (Fig. 4) were different across these six sampling plots in the Guandi

215 Mountains. In sample plot I , L. principis-rupprechtii seedlings and L. principis-rupprechtii adult

216 trees were positively correlated at a scale of $0-1 \mathrm{~m}$, and showed weakly positive correlation at

217 scales of 3.5-6.5 m and 10-15 m. Furthermore, there was no correlation at the other scales (Fig.

218 4- I ). In sample plot II, there was a slightly negative correlation at a scale greater than $19 \mathrm{~m} . L$.

219 principis-rupprechtii seedlings and adult trees showed a negative correlation at a scale of 17.5-

$22018.5 \mathrm{~m}$ and no correlation in any other scales (Fig. 4-I ). In sample plot III, there was a negative

221 correlation at scales of $0-1.5 \mathrm{~m}, 5-6.5 \mathrm{~m}$, and $13-15.2 \mathrm{~m}$, and no correlation in other scales (Fig.

$2224-$ III). In sample plot $\mathrm{I}$, there was a positive correlation at scales of $1.5-2.8 \mathrm{~m}$ and $8.2-10 \mathrm{~m}$, and

223 there was no correlation at scales of $0-1.5 \mathrm{~m}, 2.5-8.2 \mathrm{~m}$, and 10-20 m between L. principis- 
224

225

226

227

228

229

230

231

232

233

234

235

236

237

238

239

240

241

242

243

244

245

246

247

248

249

250

251

252

253

254

255

256

rupprechtii seedlings and L. principis-rupprechtii adult trees (Fig. 4-IV). In sample plot V, there was a negative correlation at a scale of $10-11 \mathrm{~m}$, and there was no correlation at scales of $0-10 \mathrm{~m}$ and 11-20 m (Fig. 4-V). In sample plot VI, there was a positive correlation between L. principisrupprechtii seedlings and L. principis-rupprechtii adult trees at scales of 2.5-4 $\mathrm{m}$ and 8-9 $\mathrm{m}$ (Fig. 4-VI), and there was no correlation at other scales.

Effect of understory herb diversity and canopy density on L. principis-rupprechtii seedlings

In these sampling plots, six environment variables (Table 2) could explain $90.2 \%$ (PC1: 65.1\%; PC2: 25.1\%) of the changes found in the number of L. principis-rupprechtii seedlings. The number of L. principis-rupprechtii seedlings was negatively correlated with the Pielou, Shannon-Wiener, and Simpson indices, and the thickness of the semi-decomposed and undecomposed layers (Fig. 5) was weakly correlated with canopy density. Overall, the understory herb diversity and the thickness of the litter layer significantly affected the number of regenerated L. principisrupprechtii seedlings.

\section{Discussion}

\section{The effect of L. principis-rupprechtii seedlings in different sampling plots}

Previous studies have shown that the seedling stage is the most important and sensitive stage during forest regeneration (Deborah et al., 1984; Kaoru et al., 1989; Wright et al., 2005), particularly in forests with limited resources and space (Frost \& Rydin, 2000). We found that the number of L. principis-rupprechtii seedlings was mainly determined by reproductive characteristics, as larger populations could produce more high-quality seeds. Natural germinated seedlings are formed when seeds are distributed under a large forest gap with favorable resources (Fig. 2), and a large number of seedlings are distributed in the community (Harms et al., 2000).

The demands of L. principis-rupprechtii seedlings for light, soil nutrients, and water increase with their growth. L. principis-rupprechtii is a typical heliophilous species and their seedlings only grow successfully when occupying a large forest gap. Limited environmental resources and space can increase self-thinning in gradually-matured seedlings (Condit et al., 2000). Therefore, to achieve stable population growth, the living environment of $L$. principis-rupprechtii seedlings must be improved.

Species spatial distribution patterns change with scale (Condit et al., 2000; Peter \& Chesson, 2000). The distribution pattern of a species at a small scale is mainly determined by seedling replenishment, while the distribution pattern at a large scale is mainly determined by habitat 
257

258

259

260

261

262

263

264

265

266

267

268

269

270

271

272

273

274

275

276

277

278

279

280

281

282

283

284

285

286

287

288

289

290

heterogeneity (Bai et al., 2012; M. et al., 2013). In this study, L. principis-rupprechtii seedlings across all sample plots showed aggregated distribution at a scale of $0-5 \mathrm{~m}$, and the distribution pattern changed from aggregated distribution to random or regular distribution as the scale increased, which is consistent with the findings of Zhang \& Meng (2007). The difference in distribution patterns at the large and small scales was caused by the aggregated distribution at a small scale, which was beneficial for L. principis-rupprechtii seedlings to shelter each other, resist the adverse environment, and improve the survival rate. The random or regular distribution at a large scale allowed the L. principis-rupprechtii seedlings to avoid intraspecific competition (e.g., for light, water, or other resources) caused by habitat heterogeneity (Jian et al., 2007). During the field investigation, we also found that L. principis-rupprechtii seedlings were mostly distributed under the forest gap, and there were more seedlings above the litter layer, especially in the thinner thickness of the litter layer. On the other hand, the decreasing number of trees created good conditions for the mass reproduction and growth of young individuals. Additionally, when the root system extended to a certain degree, the self-thinning effect changed its distribution pattern from an aggregate distribution to a random or regular distribution, and L. principis-rupprechtii adult trees were mainly in random or regular distributions, which was consistent with the findings of Jian et al. (2007) and Nathan (2006).

\section{Spatial correlation analysis of $L$. principis-rupprechtii seedlings and adult trees}

The spatial correlation of individuals of different species within a population shows the spatial distribution and functional relationships among individuals at a particular time (Shields et al., 2014). This relationship is the result of the long-term interactions between trees and seedlings, and between the population and environment, and is the measure by which the current situation and population development trend can be predicted. A positive spatial correlation reflects the mutually beneficial ecological relationship within the population while a negative spatial correlation confirms a mutually exclusive ecological relationship within the population (Zhang et al., 2012).

Previous studies have shown that the spatial distribution characteristics of adult trees affect the spatial correlation of tree growth (Getzin et al., 2008a; Walder \& Walder, 2008). When trees are aggregated, growth reflects an obvious negative correlation, and negative correlation intensity increases with aggregation intensity. Law et al. (2010) found that the spatial correlation pattern of tree growth and the spatial distribution pattern of trees are independent to a certain extent. In this study, we observed no or a weak negative correlation between adult trees and seedlings with the increase of scale (except at a small scale), which may be because adult trees have a lower demand for soil water, light, and other resources and do not compete with seedlings (Caquet et al., 2010; Chen \& Cao, 2014). As a result, there is a large distribution density of individual seedlings around 
291 adult trees. The spatial correlations between L. principis-rupprechtii seedlings and adult trees in

292 plots V and VI, I and IV, and II and III were similar (Fig. 4), and illustrated the effect of trees 293 on seedlings. We also found that there were few seedlings around trees in some sampling plots 294 (Fig. 2), which was probably caused by limited seed diffusion (Seidler \& Plotkin, 2006). Because 295 L. principis-rupprechtii seeds have seed wings and rely on the wind to spread, most seeds are 296 scattered at a small scale to form seedlings. Additionally, there is less wind in plots at high 297 elevations, which causes scattered distribution of L. principis-rupprechtii seeds in these areas. 298 Additionally, the effect of $L$. principis-rupprechtii adult trees on seedlings gradually decreased at 299 a large scale, which shows that the competition between trees and seedlings tends to be gentle and 300 seeds are unable to disperse over a long range. On the other hand, however, this shows the joint 301 action of the bio-ecological characteristics of the population. The findings in this paper are 302 consistent with those of Zhang et al. (2012) and Wang et al. (2017).

303 We also found that individuals with the same tree age were in aggregated distribution. This 304 indicates positive spatial correlation, interdependency, and consistency in the selection of habitats 305 (Andersen, 1992) because these individuals are at similar development stages and shelter each 306 other, improving the survival rate. The non-correlation between L. principis-rupprechtii adult trees 307 and seedlings at a large scale indicates that the individuals do not interfere with each other in the 308 early development stage. With an increase in scale, the correlation between L. principis309 rupprechtii adult trees and seedlings became uncorrelated or negatively correlated, indicating that

310 the increasing number of seedlings may lead to growth retardation or death. This explains why 311 there are only a small number of seedlings around L. principis-rupprechtii adult trees in some 312 geographical locations (Getzin et al., 2008b), which validates our hypothesis (1). Additionally, a 313 few L. principis-rupprechtii adult trees produced a better habitat for seedlings, which allowed them 314 to make full use of limited resources in order to grow. Overall, the distance between L. principis315 rupprechtii seedlings and adult trees affected the natural regeneration of seedlings in the Guandi 316 Mountains. The distance $(1.5-4 \mathrm{~m})$ between seedlings and adult trees can be applied to promote 317 the natural regeneration of seedlings. Therefore, the effectiveness and practicality of seedling 318 transplantation using this distance between seedlings and adult trees should be considered in 319 further research.

320 The effect of distribution between L. principis-rupprechtii adult trees and seedlings

321 Habitat heterogeneity is considered the most significant factor that leads to seedling aggregation

322 (Getzin et al., 2008b). Herb diversity potentially impacts species composition and seedling spatial 323 patterns, and significantly reduces community productivity. We found that herb diversity 324 negatively affected the number of L. principis-rupprechtii seedlings, which decreased the number 
325 of L. principis-rupprechtii seedlings (Fig. 5 and Table 2), validating our hypothesis (2). Herbs use 326 most of their biomass to produce large and long leaves, increasing the thickness of the litter layer, 327 while reducing the available light, inhibiting the growth of co-occurring species, and impeding the regeneration of seedlings.

An increasing number of herbs increases the competition for soil nutrients among seedlings, affecting species composition. Shading and mechanical hindering (e.g., in twine production) impede seed germination and seedling regeneration and can lead to seedling death. With an increase in herbaceous coverage, the number of seedlings greatly decreased, indicating that herbaceous coverage is the main factor affecting the regenerate degrees of seedlings. The scale of 1.5-4 m was consistent with the range of canopy cover in adult trees. Insufficient light can impede the growth of herbs. A shady environment is optimal for the regeneration of seedlings at an early stage, which further verifies our previous conclusion. Decreased thickness of the semidecomposed and undecomposed layers lead to a large number of nutrients being decomposed and transferred to the soil to promote the growth of seedlings. According to the results of this study, understory litter is formed at the early stage of regeneration, and the semi-decomposed and undecomposed layers are relatively thin at the scale of 1.5-4 m (Malik et al., 2020). The semidecomposed and undecomposed litter layers showed a negative effect on natural regeneration across the six sampling plots. Seeds germinated into seedlings in the litter layer, but the seed radicles in the thicker litter layer could not reach the soil and obtain sufficient nutrients for growth,

344 leading to the death of many naturally regenerated seedlings in the early development stage (Nakagawa et al., 2001; Nakagawa et al., 2003). The litter layer was thick around adult trees at a scale of $1 \mathrm{~m}$. However, L. principis-rupprechtii's thick litter layer had an auto-toxic effect on seed germination and seedling growth (Jaan et al., 2011), even though the thick semi-decomposed and undecomposed layers can preserve heat, water, and other resources. Generally, the litter thickness in these plots created an ideal stand for regenerated L. principis-rupprechtii seedlings. Thinner and and L. principis-rupprechtii seedlings was weak, which was consistent with the findings of Wenjun $\& X i$ (2020) and verifed our hypothesis (3).

\section{Conclusion}

354 This study provided a better understanding of natural regenerative success, and revealed the interactions between populations, environmental factors, and the potential causes affecting regeneration. The univariate distribution type of regenerated seedlings was aggerated at a scale of 
359 between seedlings and adult trees, ranging from 1.5 to $4 \mathrm{~m}$. Ideal artificial interference should 360 therefore be considered when determining forest management practices and adjusting the natural 361 regeneration process. In northern China's forest restoration, seedlings should be transplanted at a 362 proper distance from the adult trees in order to stimulate the natural regeneration of L. principis-

363

364

365

366

367

368

369

370

371

372

373

374

375

376

377

378

379

380

381

382

383

384

385

386

387

388

389

390

391

392

393

394

rupprechtii. Herb diversity and litter thickness pose significant negative influences on the number of regenerated seedlings. Herbs, shrubs, and unhealthy and dead trees should be removed appropriately. Extra-thick litter layers should be promptly removed to ensure a proper litter thickness. These intervention strategies can reduce the competition between enrichment species and regenerated seedlings, allowing for natural regeneration and long-term sustainable development.

\section{Acknowledgements}

We thank anonymous reviewers for the useful comments.

\section{Funding}

This work was supported by the National Natural Science Foundation of China (No. 31971644, 31901365, and 31500523); Innovation project of graduate education in Shanxi Province (No. 2020BY048); technological innovation project of colleges and universities in Shanxi province (No. 201910394); Shanxi provincial outstanding doctoral program for incentive funds for scientific research projects (No. SXYBKY2018032); Fund for introduced talents for Shanxi agricultural university (No. 2018yj09 and 2014yj19).

\section{References}

Andersen M. 1992. Spatial analysis of two-species interactions. Oecologia 91:134-140. 10.1007/BF00317252.

B SSA, C ZAMA, and A CMS. 2016. Tree species richness, diversity, and regeneration status in different oak ( Quercus spp.) dominated forests of Garhwal Himalaya, India. Journal of Asia-Pacific Biodiversity 9:293-300. 10.1016/j.japb.2016.06.002.

Bai X, Queenborough SA, Wang X, Jian Z, Li B, Yuan Z, Xing D, Lin F, and Ji Y. 2012. Effects of local biotic neighbors and habitat heterogeneity on tree and shrub seedling survival in an old-growth temperate forest. Oecologia 170:755-765. 10.1007/s00442-0122348-2.

Barbeito I, Pardos M, Calama R, and Canellas I. 2008. Effect of stand structure on Stone pine (Pinus pinea L.) regeneration dynamics. Forestry 81:617-629. 10.1093/forestry/cpn037.

Camarero JJ, Gutiérrez E, Fortin MJ, and Ribbens E. 2010. Spatial patterns of tree recruitment in a relict population of Pinus uncinata: forest expansion through stratified diffusion. Journal of Biogeography 32:1979-1992. 10.1111/j.1365-2699.2005.01333.x. 
395

396

397

398

399

400

401

402

403

404

405

406

407

408

409

410

411

412

413

414

415

416

417

418

419

420

421

422

423

424

425

426

427

428

429

430

431

432

433

Caquet B, Montpied P, Dreyer E, Epron D, and Collet C. 2010. Response to canopy opening does not act as a filter to Fagus sylvatica and Acer sp. advance regeneration in a mixed temperate forest. Annals of Forest Science 67:105-105. 10.1051/forest/2009086.

Chen YM, and Cao Y. 2014. Response of tree regeneration and understory plant species diversity to stand density in mature Pinus tabulaeformis plantations in the hilly area of the Loess Plateau, China. Ecological Engineering 73:238-245. 10.1016/j.ecoleng.2014.09.055.

Cheng XQ, Han HR, Kang FF, Song YL, and Liu K. 2014. Point pattern analysis of different life stages of Quercus liaotungensis in Lingkong Mountain, Shanxi Province, China. Journal of Plant Interactions 9:233-240. 10.1080/17429145.2013.818167.

Christian A, Andreas F, Anton F, Gossner MM, Peter M, Rupert S, Thomas FM, Peter A, Jürgen K, and Bettina O. 2018. Key ecological research questions for Central European forests. Basic and Applied Ecology 32:3-25. 10.1016/j.baae.2018.07.006.

Chu GM, Wang M, and Zhang SX. 2014. Spatial patterns and associations of dominant woody species in desert-oasis ecotone of South Junggar Basin, NW China. Journal of Plant Interactions 9:738-744. 10.1080/17429145.2014.918663.

Condit R, Ashton PS, Baker P, Bunyavejchewin S, Gunatilleke S, Gunatilleke N, Hubbell SP, Foster RB, Itoh A, LaFrankie JV, Lee HS, Losos E, Manokaran N, Sukumar R, and Yamakura T. 2000. Spatial patterns in the distribution of tropical tree species. Science 288:1414-1418. 10.1126/science.288.5470.1414.

Crawford PHC, and Hoagland BW. 2010. Using species distribution models to guide conservation at the state level: the endangered American burying beetle (Nicrophorus americanus) in Oklahoma. Journal of Insect Conservation 14:511-521. 10.1007/s10841010-9280-8.

D. RB. 1977. Modelling Spatial Patterns. Journal of the Royal Statistical Society Series B (Methodological) 39:172-212. 10.2307/2984796.

Deborah, A., Clark, David, B., and Clark. 1984. Spacing Dynamics of a Tropical Rain Forest Tree: Evaluation of the Janzen-Connell Model. American Naturalist 124:769-788. $10.2307 / 2461300$.

Devaney JL, Jansen MAK, and Whelan PM. 2014. Spatial patterns of natural regeneration in stands of English yew (Taxus baccata L.); Negative neighbourhood effects. Forest Ecology and Management 321:52-60. 10.1016/j.foreco.2013.06.060.

Dong BQ, Zhao KJ, Wang ZB, Jia ZK, Ma LY, and Xia XL. 2018. Forest recovery after clearcutting in Chinese pine (Pinus tabuliformis) plantations of North China. Journal of Arid Land 10:233-248. 10.1007/s40333-018-0004-3.

Ferrier S, Watson G, Pearce J, and Drielsma M. 2002. Extended statistical approaches to modelling spatial pattern in biodiversity in northeast New South Wales. I. Species-level modelling. Biodiversity \& Conservation 11:2275-2307. 10.1023/A:1021302930424.

Frost I, and Rydin H. 2000. Spatial pattern and size distribution of the animal-dispersed tree Quercus robur in two spruce-dominated forests. ECOSCIENCE 7:38-44.

Peer) reviewing PDF | (2021:04:60482:3:0:NEW 15 Sep 2021) 
434

435

436

437

438

439

440

441

442

443

444

445

446

447

448

449

450

451

452

453

454

455

456

457

458

459

460

461

462

463

464

465

466

467

468

469

470

471

$10.1080 / 11956860.2000 .11682569$.

Gao X, Li H, and Zhao X. 2020. Impact of land management practices on tree water use strategy and responses to drought in a dryland plantation. Land Degradation and Development 32:439-452. 10.1002/LDR.3687.

Getzin S, Wiegand K, Schumacher J, and Gougeon FA. 2008a. Scale-dependent competition at the stand level assessed from crown areas. Forest Ecology and Management 255:24782485. 10.1016/j.foreco.2008.01.007.

Getzin S, Wiegand T, Wiegand K, and He F. 2008b. Heterogeneity influences spatial patterns and demographics in forest stands. Journal of Ecology 96:807-820. 10.1111/j.13652745.2008.01377.x.

Guo H, and Wang XA. 2019. Seedlings Recruitment of a Timberline Tree (Larix chinensis Beissn) in Taibai Mountain, China. Russian Journal of Ecology 50:187-192. 10.1134/S106741361902005x.

Haase P. 1995. Spatial pattern analysis in ecology based on Ripley's K - function: Introduction and methods of edge correction. Journal of Vegetation Science 6:572-582. $10.2307 / 3236356$.

Hambly B, Stoyan D, and Stoyan H. 1994. Fractals, Random Shapes and Point Fields. Journal of the Royal Statistical Society 159:194-195. 10.2307/2983497.

Harms KE, Wright SJ, Calderon O, Hernandez A, and Herre EA. 2000. Pervasive densitydependent recruitment enhances seedling diversity in a tropical forest. Nature 404:493495. 10.1038/35006630.

He F, Legendre P, and Lafrankie JV. 1997. Distribution patterns of tree species in a Malaysia tropica rain forest. Journal of Vegetation Science 8:105-114. 10.2307/3237248.

Hernandez-Barrios JC, Anten NPR, and Martinez-Ramos M. 2015. Sustainable harvesting of non-timber forest products based on ecological and economic criteria. Journal of Applied Ecology 52:389-401. 10.1111/1365-2664.12384.

Itoh A, Yamakura T, Ogino K, Seng Lee H, and Ashton PS. 1997. Spatial distribution patterns of two predominant emergent trees in a tropical rainforest in Sarawak, Malaysia. Plant Ecology 132:121-136. 10.1023/a:1009779424279.

Jaan, Liira, Toivo, SeppKaupo, and Kohv. 2011. The ecology of tree regeneration in mature and old forests: combined knowledge for sustainable forest management. Journal of Forest Research 16:184-193. 10.1007/s10310-011-0257-6.

Janzen DH. 1970. Janzen, D. H. Herbivores and number of tree species in tropical forests. American Naturalist. The American Naturalist 104:501-528. 10.1086/282687.

Jian Z, Zhan-Qing H, Bo S, Ji Y, Bu-Hang L, and Xiao-Lin Y. 2007. Spatial distribution patterns and associations of Pinus koraiensis and Tilia amurensis in broad-leaved Korean pine mixed forest in Changbai Mountains. The journal of applied ecology 18:1681-1687. 10.3321/j.issn:1000-0933.2008.06.002. 
472 Kaoru, Kitajima, Carol, K., and Augspurger. 1989. Seed and Seedling Ecology of a

473

474

475

476

477

478

479

480

481

482

483

484

485

486

487

488

489

490

491

492

493

494

495

496

497

498

499

500

501

502

503

504

505

506

507

508

509

510

Monocarpic Tropical Tree, Tachigalia Versicolor. Ecology 70:1102-1114. 10.2307/1941379.

Law R, Illian J, Burslem D, Gratzer G, Gunatilleke C, and Gunatilleke I. 2010. Ecological information from spatial patterns of plants: insights from point process theory. Journal of Ecology 97:616-628. 10.1111/j.1365-2745.2009.01510.x.

Liu ZQ, Yu XX, and Jia GD. 2019. Water uptake by coniferous and broad-leaved forest in a rocky mountainous area of northern China. Agricultural and Forest Meteorology 265:381389. 10.1016/j.agrformet.2018.11.036.

M., Chen, Z.-S., Waagepetersen, R., Hao, Z., F., Shen, and G. 2013. Quantifying effects of habitat heterogeneity and other clustering processes on spatial distributions of tree species. Ecology: A Publication of the Ecological Society of America 94:2436-2443. 10.1890/121983.1.

Malik AA, Swenson T, Weihe C, Morrison EW, Martiny JBH, Brodie EL, Northen TR, and Allison SD. 2020. Drought and plant litter chemistry alter microbial gene expression and metabolite production. ISME J 14:2236-2247. 10.1038/s41396-020-0683-6.

Man R, Rice JA, and Blake MDG. 2013. Performance of planted spruce and natural regeneration after pre- and post-harvest spraying with glyphosate and partial cutting on an Ontario (Canada) boreal mixedwood site. Forestry 86:475-480. 10.1093/forestry/cpt018.

Mc, Conigley, Lally, O'Callaghan, O'Dea, Little, and Kelly-Quinn. 2015. The vegetation communities of unmanaged aquatic buffer zones within conifer plantations in Ireland. Forest Ecology and Management 2015,353:59-66. 10.1016/j.foreco.2015.05.009.

Nakagawa, Kurahashi, Kaji, and Hogetsu. 2001. The effects of selection cutting on regeneration of Picea jezoensis and Abies sachalinensis in the sub-boreal forests of Hokkaido, northern Japan. FOREST ECOL MANAGE 146:15-23. 10.1016/S0378-1127(00)00445-X.

Nakagawa M, Kurahashi A, and Hogetsu T. 2003. The regeneration characteristics of Picea jezoensis and Abies sachalinensis on cut stumps in the sub-boreal forests of Hokkaido Tokyo University Forest. Forest Ecology \& Management 180:353-359. 10.1016/S03781127(02)00654-0.

Nathan R. 2006. Long-Distance Dispersal of Plants. Science 313:786-788. 10.1126/science. 1124975 .

Peng SL, Wang DX, Zhao H, and Yang T. 2008. Discussion the status quality of plantation and near nature forestry management in China. Journal of Northwest Forestry University 23:184-188. 10.3724/SP.J.1005.2008.01033.

Peter, and Chesson. 2000. MECHANISMS OF MAINTENANCE OF SPECIES DIVERSITY. Annual Review of Ecology \& Systematics 31:343-358+C341+359-366. 10.1146/annurev.ecolsys.31.1.343.

Ram A, Rikie S, Haruo S, and Shibu J. 2014. Natural Forest Biomass Estimation Based on Plantation

Information

Using

PALSAR

Data.

PLoS

One 9:e86121.

Peer] reviewing PDF | (2021:04:60482:3:0:NEW 15 Sep 2021) 
511

512 Seidler TG, and Plotkin JB. 2006. Seed Dispersal and Spatial Pattern in Tropical Trees. PLoS $513 \quad$ Biology 4:e344. 10.1371/journal.pbio.0040344.

514 Seiwa K, Etoh Y, Hisita M, Masaka K, Imaji A, Ueno N, Hasegawa Y, Konno M, Kanno H, 515 and Kimura M. 2012. Roles of thinning intensity in hardwood recruitment and diversity 516 517

518

519

520

521

522

523

524

525

526

527

528

529

530

531

532

533

534

535

536

537

538

539

540

541

542

543

544

545

546

547

548

549 in a conifer, Criptomeria japonica plantation: A 5-year demographic study. Forest Ecology \& Management 269:177-187. 10.1016/j.foreco.2011.12.014.

Shields JM, Jenkins MA, Saunders MR, Hao Z, and Parks AM. 2014. Age Distribution and Spatial Patterning of an Invasive Shrub in Secondary Hardwood Forests. European Journal of Marketing 60:830-840. 10.5849/forsci.13-079.

Singh G, and Rawat GS. 2012. Quantitative Analysis of Tree Species Diversity in Different Oak (Quercus spp.) Dominated Forests in Garhwal Himalaya, India. Notulae Scientia Biologicae 4:132-140. 10.15835/nsb.4.4.8200.

Stoyan, Stoyan D, and Helga. 1994. Fractals, Random Shapes and Point Fields: Methods of Geometrical Statistics: Fractals, Random Shapes and Point Fields: Methods of Geometrical Statistics.

Walder O, and Walder K. 2008. Analysing interaction effects in forests using the mark correlation function. Iforest Biogeosciences \& Forestry 1:34-38. 10.3832/ifor04490010034.

Wang X, Ye J, Li B, Jian Z, Lin F, and Hao Z. 2010. Spatial distributions of species in an oldgrowth temperate forest, northeastern China. Canadian Journal of Forest Research 40:1011-1019. 10.1139/X10-056.

Wang Z, Yang H, Dong B, Zhou M, Ma L, Jia Z, and Duan J. 2017. Regeneration response to canopy gap size in a Chinese pine plantation: Species diversity patterns, size structures and spatial distributions. Forest Ecology and Management 397:97-107. 10.1016/j.foreco.2017.04.037.

Wang Z, Yang H, Wang D, and Zhao Z. 2019. Response of height growth of regenerating trees in a Pinus tabulaeformis Carr. plantation to different thinning intensities. Forest Ecology and Management 444:280-289. 10.1016/j.foreco.2019.04.042.

Wei DY, A-Peng DU, Xie YJ, Liang-Liang HE, and Zhang PJ. 2010. Application of "Nearnature Forestry" Theory in Eucalypt Plantation Management. Eucalypt Science \& Technology 27:48-54.

Wenjun L, and Xi W. 2020. Factors promoting the natural regeneration of Larix principisrupprechtii plantation in the Lvliang Mountains of central China. PeerJ 8:e9339. 10.7717/peerj.9339.

Wiegand T, Kissling WD, Cipriotti PA, and Aguiar MR. 2006. Extending point pattern analysis for objects of finite size and irregular shape. Journal of Ecology 94:825-837. 10.1111/j.1365-2745.2006.01113.x.

Wiegand T, and Moloney KA. 2004. Rings, circles, and null - models for point pattern analysis

Peer] reviewing PDF | (2021:04:60482:3:0:NEW 15 Sep 2021) 
550

551

552

553

554

555

556

557

558

559

560

561

562

563

564

in ecology. Oikos 104:209-229. 10.1111/j.0030-1299.2004.12497.x.

Wright SJ, Muller-Landau HC, Calderón O, and Hernandéz A. 2005. ANNUAL AND SPATIAL VARIATION IN SEEDFALL AND SEEDLING RECRUITMENT IN A NEOTROPICAL FOREST. Ecology 86:848-860. 10.1890/03-0750.

Yang XQ, Zhang P, Wu QT, Yan HB, and Yu MK. 2017. Effects of Simulated Wind Load on Leaf Photosynthesis and Carbohydrate Allocation in Eight Quercus Species. Journal of Biobased Materials \& Bioenergy 11:652-657. 10.1166/jbmb.2017.1721.

Zhang J, and Meng D. 2007. Point pattern analysis of different age-classes of Larix principisrupprechtii in Luya Mountain Reserve, Shanxi Province, China. Frontiers of Biology in China 2:69-74. 10.1007/s11515-007-0012-8.

Zhang YT, Jimei LI, Chang SL, Xiang LI, and Jianjiang LU. 2012. Spatial distribution pattern of Picea schrenkiana population in the Middle Tianshan Mountains and the relationship with topographic attributes. Journal of Arid Land 4:457-468. 10.3724/SP.J.1227.2012.00457. 
Figure 1

The study site, Larix principis-rupprechtii forests in Jiaocheng County (A). Red dots indicate the sampling plots (I-VI), gray boxes indicate the six sampling areas (B).

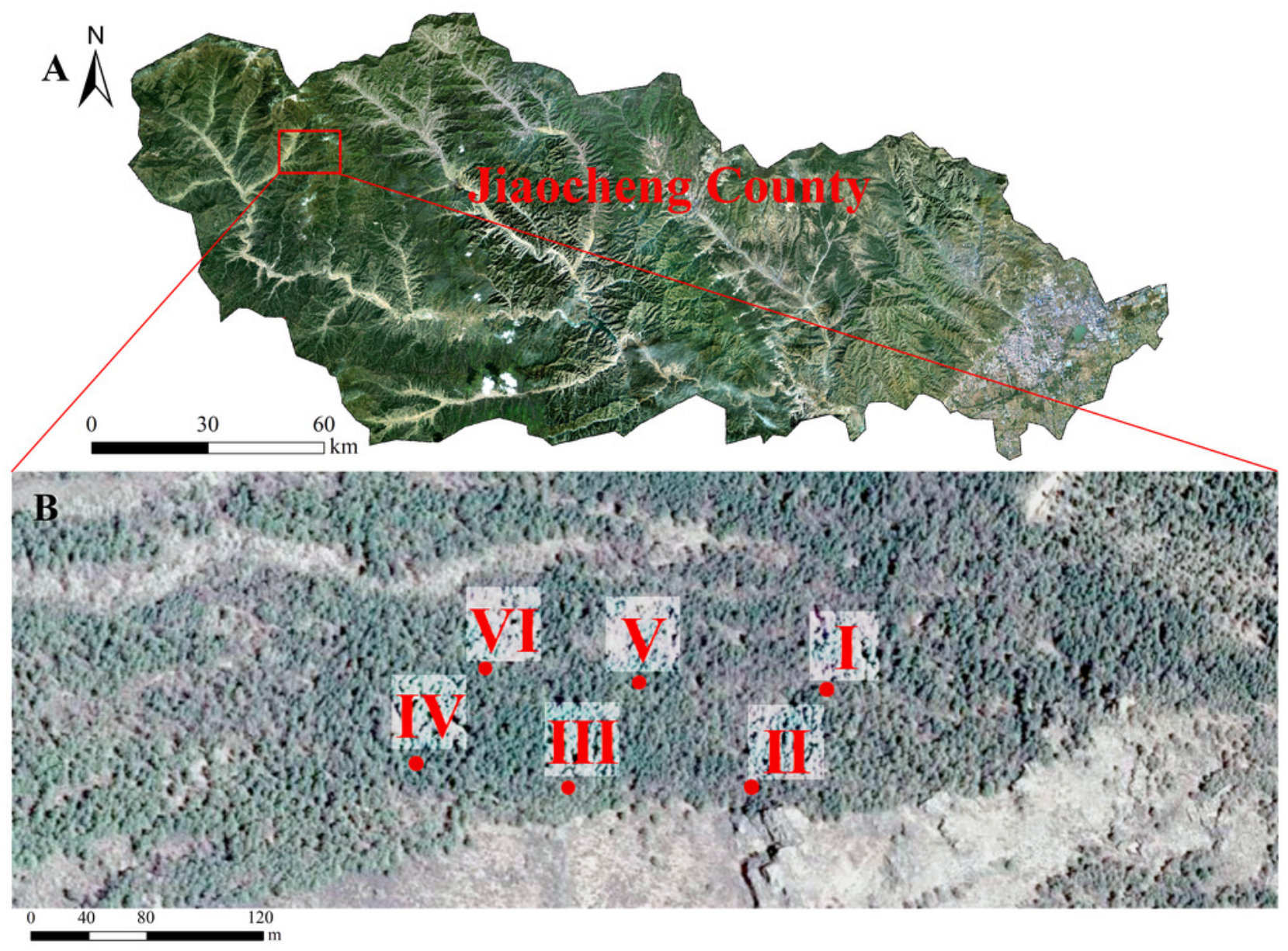


Figure 2

The distribution of $L$. principis-rupprechtii seedlings and L. principis-rupprechtii adult trees in the six sampling plots (I, II, III, IV, V, and VI).

L. principis-rupprechtii seedlings are represented by a circle $(O)$ and L. principis-rupprechtii adult trees by a triangle $(\mathbf{\Lambda})$.

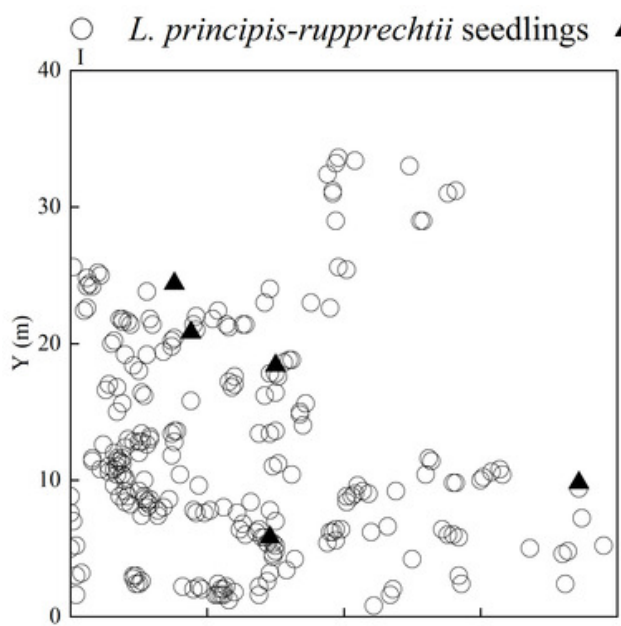

L. principis-rupprechtii adult trees
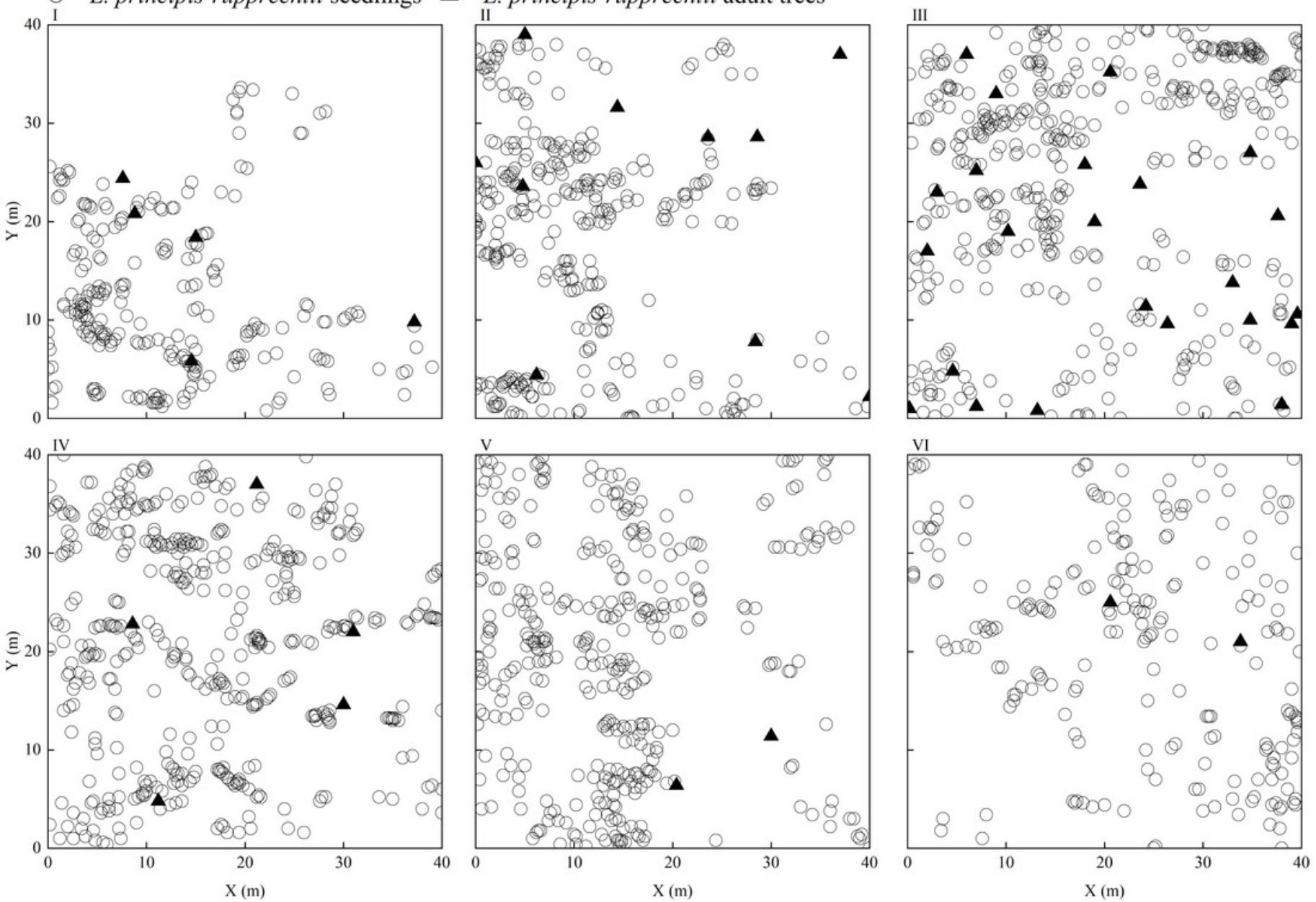
Figure 3

Spatial distribution pattern of different plots (I-VI) of L. principis-rupprechtii regenerated seedlings in the Guandi Mountains.

$r$ is the radius of the sampling circle with the target tree as the centroid; the upper dotted line represents the upper envelope trace; the lower grey solid line represents the lower envelope trace; the blank middle part represents the $99 \%$ confidence interval.
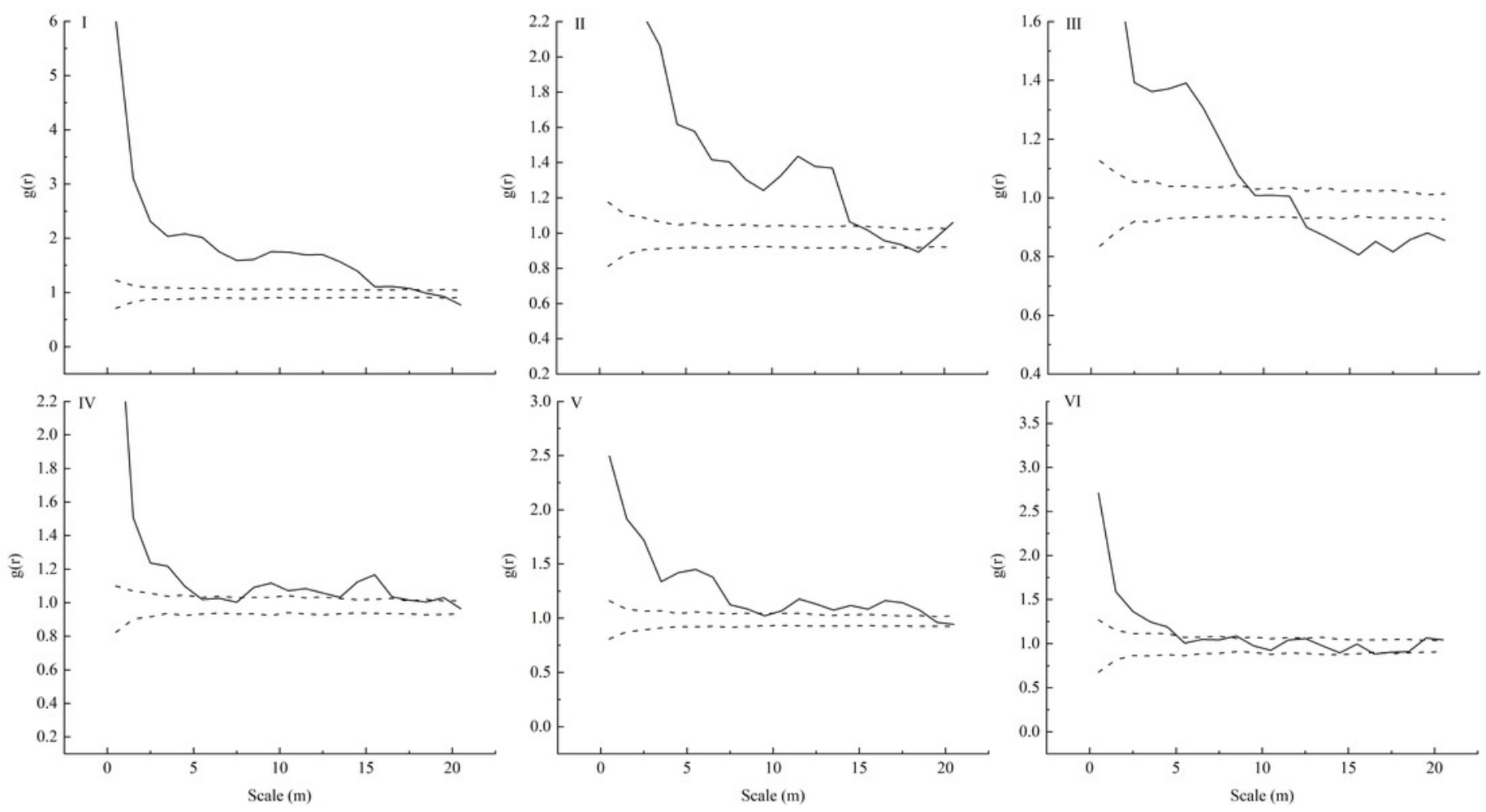


\section{Figure 4}

Bivariate analysis using null models (independence) for the competition (I-VI) between a pair of $L$. principis-rupprechtii seedlings and L. principis-rupprechtii adult trees.

L. principis-rupprechtii seedlings formed pattern 1 and random shifts of $L$. principisrupprechtii adult trees formed pattern 2 across the study region are shown using a torus. Black solid lines represent the function values of the pair-correlation function ( $g 12(r))$, upper dotted lines represent the upper envelope trace, lower dotted lines represent the lower envelope trace, and the middle part represents the $99 \%$ confidence interval.
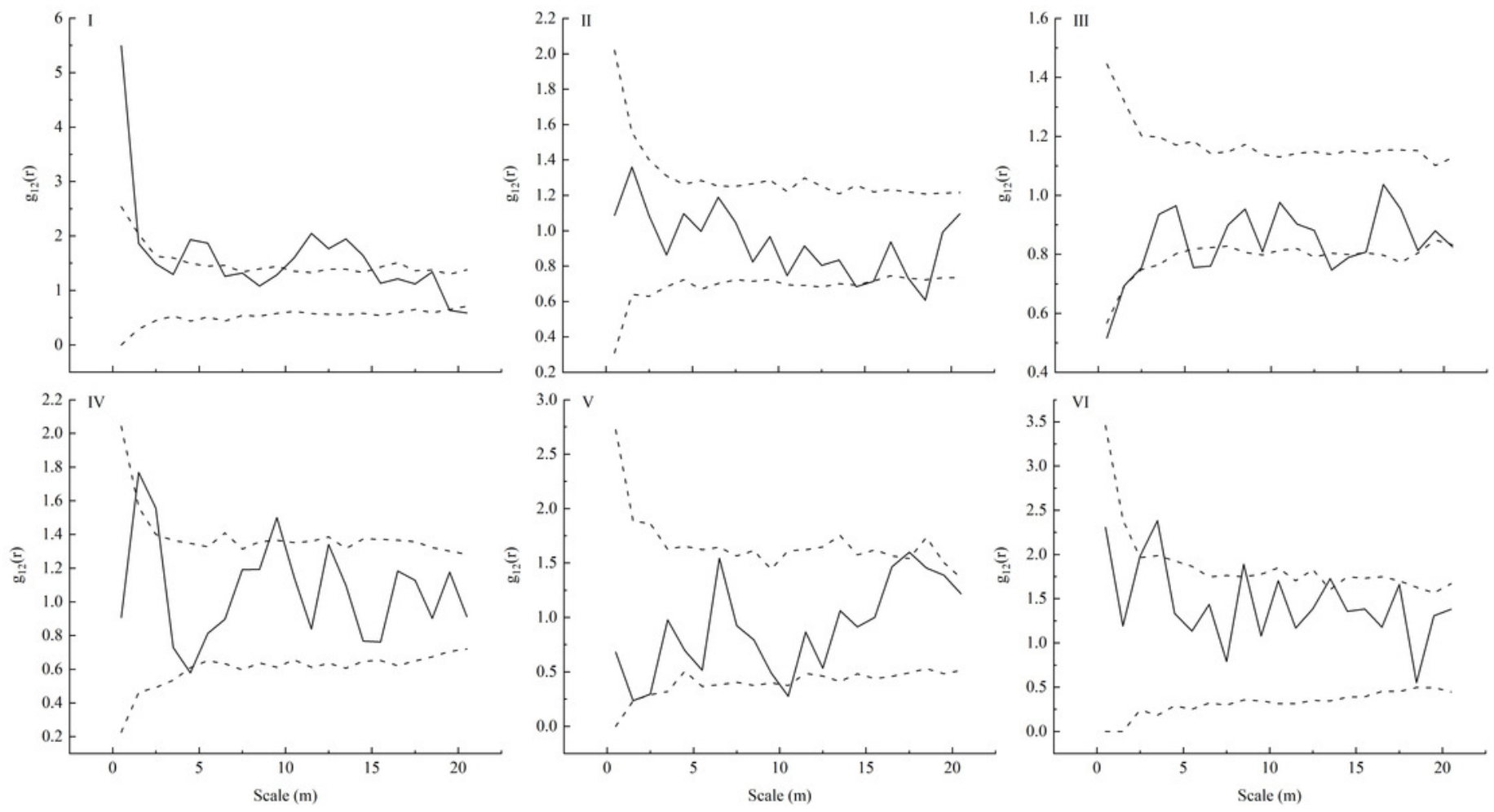
Figure 5

Principal component analysis of factors affecting the number of $L$. principis-rupprechtii seedlings in different sampling plots.

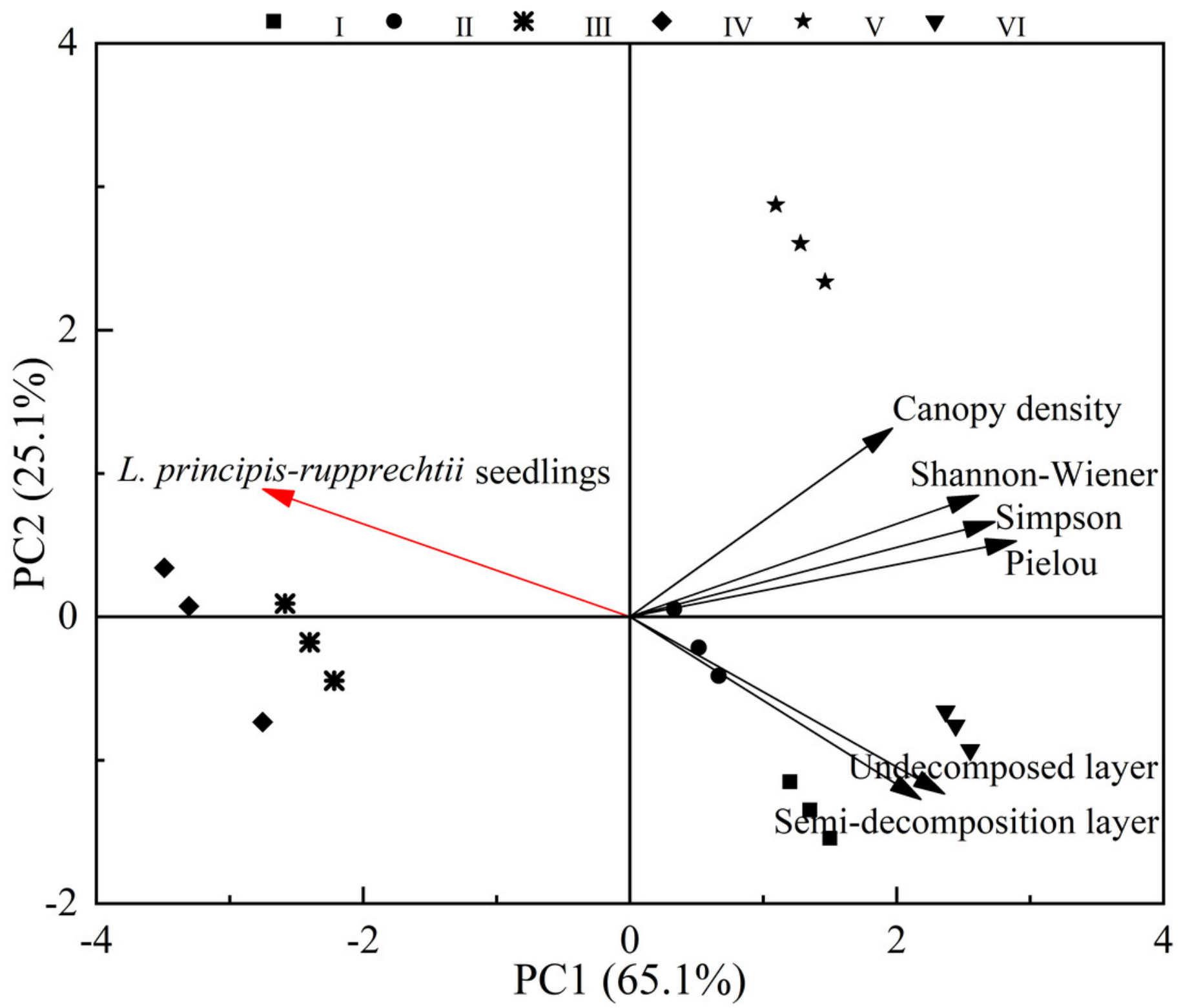




\section{Table $\mathbf{1}$ (on next page)}

Basic status of sample trees. 
1 Table 1

\begin{tabular}{|c|c|c|c|c|c|c|}
\hline Sample plot & I & II & III & IV & $\mathrm{V}$ & VI \\
\hline Tree age (a) & 59 & 50 & 62 & 64 & 65 & 59 \\
\hline Longitude & $111^{\circ} 32^{\prime} 33^{\prime \prime}$ & $111^{\circ} 32^{\prime} 28^{\prime \prime}$ & $111^{\circ} 32^{\prime} 25^{\prime \prime}$ & $111^{\circ} 32^{\prime} 24^{\prime \prime}$ & $111^{\circ} 32^{\prime} 26^{\prime \prime}$ & $111^{\circ} 32^{\prime} 25^{\prime \prime}$ \\
\hline Latitude & $37^{\circ} 51^{\prime} 21^{\prime \prime}$ & $37^{\circ} 51^{\prime} 19^{\prime \prime}$ & $37^{\circ} 51^{\prime} 17^{\prime \prime}$ & $37^{\circ} 51^{\prime} 15^{\prime \prime}$ & $37^{\circ} 51^{\prime} 20^{\prime \prime}$ & $37^{\circ} 51^{\prime} 20^{\prime \prime}$ \\
\hline Altitude (m) & 2066 & 2060 & 2029 & 2018 & 2025 & 2023 \\
\hline Slope $\left({ }^{\circ}\right)$ & 13 & 23 & 25 & 22 & 18 & 21 \\
\hline Aspect & NW & NW & NW & NW & NW & NW \\
\hline Density (tree/ha) & 125 & 250 & 175 & 125 & 50 & 50 \\
\hline Crown density (\%) & 30 & 20 & 10 & 10 & 50 & 20 \\
\hline $\mathrm{DBH}(\mathrm{cm})$ & $35.7 \pm 2.9$ & $31.5 \pm 8.0$ & $24.1 \pm 13.6$ & $32.5 \pm 12.2$ & $34.7 \pm 2.1$ & $37.9 \pm 2.2$ \\
\hline Height (m) & $23.9 \pm 3.0$ & $17.8 \pm 5.4$ & $19.8 \pm 8.7$ & $16.5 \pm 3.7$ & $14.5 \pm 0.7$ & $24.0 \pm 0.1$ \\
\hline $\begin{array}{l}\text { Regeneration density } \\
\text { (tree/ha) }\end{array}$ & 6000 & 8175 & 10725 & 11225 & 9325 & 5500 \\
\hline Main Vegetation & $\begin{array}{l}\text { Rosa multiflora, } \\
\text { Acer tataricum, } \\
\text { Geranium wilfordii, } \\
\text { Chrysanthemum } \\
\text { chanetii, } \\
\text { Thymus mongolocus }\end{array}$ & $\begin{array}{l}\text { Acer tataricum, } \\
\text { Berberis amurensis, } \\
\text { Aster trinervius, } \\
\text { Chrysanthemum } \\
\text { chanetii }\end{array}$ & $\begin{array}{l}\text { Spiraea salicifolia, } \\
\text { Acer tataricum, } \\
\text { Rosa multiflora, } \\
\text { Fragaria orientalis, } \\
\text { Lathyrus humilis }\end{array}$ & $\begin{array}{l}\text { Rosa multiflora, } \\
\text { Acer tataricum, } \\
\text { Chrysanthemum } \\
\text { chanetii, } \\
\text { Fragaria orientalis, } \\
\text { Carex duriuscula }\end{array}$ & $\begin{array}{l}\text { Spiraea salicifolia, } \\
\text { Acer tataricum, } \\
\text { Rosa multiflora, } \\
\text { Berberis amurensis, } \\
\text { Astragalus } \\
\text { mongholicus }\end{array}$ & $\begin{array}{l}\text { Rosa multiflora, } \\
\text { Spiraea salicifolia, } \\
\text { Acer tataricum, } \\
\text { Vicia amoena, } \\
\text { Fragaria orientalis }\end{array}$ \\
\hline
\end{tabular}

2 Note: NW is the northwest aspect of each plot. 


\section{Table 2 (on next page)}

The basic information of herb diversity for understory and canopy density in the six sampling plots. 
1 Table 2

\begin{tabular}{|c|c|c|c|c|c|c|c|}
\hline $\begin{array}{l}\text { Sampl } \\
\text { e plot }\end{array}$ & $\begin{array}{l}\text { L. principis- } \\
\text { rupprechtii } \\
\text { seedlings (number) }\end{array}$ & $\begin{array}{l}\text { The thickness } \\
\text { of } \\
\text { undecompose } \\
\text { d layer }(\mathrm{cm})\end{array}$ & $\begin{array}{l}\text { The thickness of } \\
\text { semi- } \\
\text { decomposition layer } \\
\text { (cm) }\end{array}$ & $\begin{array}{c}\text { Shannon- } \\
\text { Wiener index }\end{array}$ & $\begin{array}{l}\text { Pielo } \\
\mathrm{u} \\
\text { inde } \\
\mathrm{x}\end{array}$ & $\begin{array}{c}\text { Simps } \\
\text { on } \\
\text { index }\end{array}$ & $\begin{array}{c}\text { Canop } \\
\text { y } \\
\text { density }\end{array}$ \\
\hline I & 240 & 1.8 & 3.0 & 2.2 & 0.97 & 0.79 & 0.3 \\
\hline II & 327 & 1.5 & 2.3 & 2.4 & 0.98 & 0.80 & 0.2 \\
\hline III & 429 & 1.3 & 1.5 & 2.0 & 0.92 & 0.78 & 0.1 \\
\hline IV & 449 & 1.2 & 1.3 & 2.0 & 0.93 & 0.72 & 0.1 \\
\hline V & 373 & 1.3 & 1.5 & 2.8 & 0.99 & 0.85 & 0.5 \\
\hline VI & 220 & 1.7 & 3.2 & 2.8 & 0.98 & 0.96 & 0.2 \\
\hline
\end{tabular}

2 